\title{
Improved Fat Clearance Techniques for the Examination of Breast Cancer Lymph Nodes
}

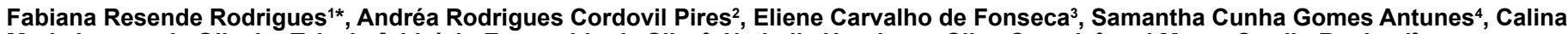
Maria Loures de Oliveira Teixeira ${ }^{5}$, Licínio Esmeraldo da Silva ${ }^{2}$, Nathalie Henriques Silva Canedo ${ }^{2}$ and Mayra Carrijo Rochael ${ }^{2}$

${ }^{1}$ Department of Pathology, Universidade Federal Fluminense, Brazil

${ }^{2}$ Department of Pathology Anatomy, Universidade Federal Fluminense, Brazil

${ }^{3}$ Department Cell and Molecular Biology, Universidade Federal Fluminense, Brazil

${ }^{4}$ Gyn-Ob Service, Universidade Federal Fluminense, Brazil

${ }^{5}$ Mastology Service, Universidade Federal Fluminense, Brazil

\begin{abstract}
Introduction: The isolation of lymph nodes less than $4.0 \mathrm{~mm}$ in diameter from the fatty tissue of surgical breast cancer specimens through the traditional method of tactile perception is difficult, time consuming and failed the identification of smaller lymph nodes. The reported numbers of lymph nodes detected through this technique vary widely in the literature demonstrating its inappropriateness. The use of fat clearance techniques however may contribute to the isolation of additional nodes, allowing for appropriate pathological staging of the disease.
\end{abstract}

Objective: To evaluate the impact of the use of fat clearance machinery and solutions in the dissection and identification of lymph nodes from axillary dissections of patients with breast cancer.

Materials and methods: Fat clearance techniques (cooker, electric spiral, modified Koren clearing solution and formaldehyde-acetic alcohol solution) were applied to 100 breast cancer axillary dissections from males and females with no age restriction over a period of two years (2009-2011).

Results: Through the use of fat clearance methods, additional 174 metastases in 564 lymph nodes were found, more than the classical method, from which 449 metastases in 1426 lymph nodes were identified. There was no statistical difference between the fat clearance methods; however the cooker method demonstrated greater efficiency than the modified Koren clearing solution method.

Conclusion: The fat clearance methods described here have various advantages over the classical method. These methods are viable, rapid, practical, inexpensive and do not alter the quality of histological analysis or immunohistochemical reactions. The findings show that examination of a minimum of 20 isolated lymph nodes is necessary for optimal identification and diagnosis of lymph node metastases. The main outcome from this study were the immediate benefits generated by adopting new technical procedures resulting in a change in pathological staging classification in $14 \%$ of the patients.

Keywords: Breast cancer; Lymph nodes; Neoplasm staging; Paraffin blocks; Revealing/clearance solutions

\section{Introduction}

Lymph node status is considered the most important prognostic factor in breast cancer diagnosis, together with tumor size, histological grade, angiolymphatic invasion and the detection of hormone receptors and HER-2 [1]. Four or more affected lymph nodes, nodal capsular invasion, capsular extravasation, and nodal coalescence by metastases are indicative of a poor prognosis. The identification of any of these findings should always be reported as the presence of these risk factors may be indicative of breast cancer recurrence; however this is controversial in the literature [2].

Studies have shown that the chances of survival of many patients worsens with the increased detection of positive nodes, since the probability of finding a predictive positive node increases with the number of lymph nodes examined [3]. There is evidence that many metastatic foci are found in lymph nodes measuring $5 \mathrm{~mm}$ or less [4].

There is no consensus as to the minimum number of lymph nodes to be dissected for accurate staging, especially in cases of pN0. The UICC [5], by the TNM system, suggest a minimum of 12 lymph nodes should be dissected; Sommer, Thomas \& Dixon [6] suggest 16 and Millis et al. [7] suggest 24 . Salama et al. [8] found that detection of less than 10 lymph nodes by axillary dissection is statistically related to a decrease in survival time from $10 \%$ to $15 \%$.

Ideally, all lymph nodes should be removed by the surgeon and examined by the pathologist, which is empirically impossible to carry out by the traditional manual, classical or conventional methods [9]. The conventional method was performed by sectioning adipose tissue with a blade in parallel intervals of $4.0 \mathrm{~mm}$, initially seeking large lymph nodes, greater than $4.0 \mathrm{~mm}$, by direct vision and smaller lymph nodes, less than $4.0 \mathrm{~mm}$, by tactile perception through palpation of the adipose tissue. The dissection should be carried out meticulously within the limitations of the conventional method, since lymph nodes can be

*Corresponding author: Fabiana Resende Rodrigues, Universidade Federa Fluminense (UFF), Departament of Pathology, Hospital Universitário Antonio Pedro, Departamento de Patologia, Rua Marques do Paraná, 303 - 4o andar Centro, Niterói, Rio de Janeiro 24033-900, Brazil, Tel: 55-21-2729-9108; Fax: 55 21-2729-9033; E-mail: resendefr@yahoo.com.br

Received January 23, 2014; Accepted May 15, 2014; Published May 20, 2014

Citation: Rodrigues FR, Pires ARC, de Fonseca EC, Antunes SCG, de Oliveira Teixeira CML, et al. (2014) Improved Fat Clearance Techniques for the Examination of Breast Cancer Lymph Nodes. J Cancer Sci Ther 6: 188-194. doi:10.4172/19485956.1000270

Copyright: (c) 2014 Rodrigues FR, et al. This is an open-access article distributed under the terms of the Creative Commons Attribution License, which permits unrestricted use, distribution, and reproduction in any medium, provided the original author and source are credited. 
Citation: Rodrigues FR, Pires ARC, de Fonseca EC, Antunes SCG, de Oliveira Teixeira CML, et al. (2014) Improved Fat Clearance Techniques for the Examination of Breast Cancer Lymph Nodes. J Cancer Sci Ther 6: 188-194. doi:10.4172/1948-5956.1000270

juxtaposed to blood vessels or larger lymph nodes, which probably cause their loss during dissection by the classical method.

There are numerous procedures to evaluate and facilitate the isolation of lymph nodes lost with simple palpation. Clearing of the axillary specimen is not necessary to identify cases with macroscopic positive nodes, but it is of paramount importance to identify minute axillary lymph nodes smaller than $2 \mathrm{~mm}$ to improve the accuracy of staging of lymph nodes in breast cancer. The methods used should be easy, fast and inexpensive. Table 1 contains a list of authors who investigated lymph node dissection using the traditional method and using fat clearance methods in breast cancer cases.

Durkin and Haagensen [10] report that Monroe, in 1948, was probably the first researcher to use fat clearance methods to identify lymph nodes in 87 radical mastectomy specimens and found 31 lymph nodes per specimen. Most authors agree that there is benefit to the number of lymph nodes dissected however there is controversy as to whether the extra time and resources consumed by these processes justify its routine use [11]. The present study addresses this controversy.

\section{Objective}

To evaluate the impact of using fat clearance methods for the identification of lymph nodes in axillary dissections from patients with breast cancer.

\section{Materials and Methods}

All material was derived from 100 surgical axillary dissection specimens previously fixed in $10 \%$ buffered formalin, from patients of both sexes with breast cancer, irrespective of age, received at the
Department of Pathology, Hospital Universitário Antonio Pedro (HUAP) over a period of two years (2009 to 2011).

After dissection of lymph nodes of all cases by the classical method the remaining fat of each specimen were grouped randomly in groups of 25 cases and each group was submitted one of the methods for clearing fat described below (Figure 1).

The distinctive fat-clearing methods were:

1) Electric aluminum spiral boiler (Resiswal'), 1000W 127V, placed in a container or stainless steel saucepan with water covering the material and heated for 15 to 30 minutes, following manufacturers recommendations: the maximum water level should not reach the spiral cable; the boiler should never be turned on or off out of the water; the spiral extremity should always be covered with water; and the manipulation of the material should only be carried out after the tissue had cooled (Figure 2A).

2) Electric pan (Vicini $\left.{ }^{\circ}\right)$ with a temperature display ranging from $80^{\circ} \mathrm{C}$ to $180^{\circ} \mathrm{C}$ and filled with water. A temperature of $100^{\circ} \mathrm{C}$ for 15 to 30 minutes was used and material was handled only after cooling. The average price for this Electric pan is US\$100.00 (Figure 2B).

3) A modified fat-clearing solution described by Koren et al. [4]. The solution was made by mixing $65 \mathrm{~mL}$ of commercial $99.3 \%$ ethyl alcohol, $20 \mathrm{~mL}$ of diethyl ether, $5 \mathrm{~mL}$ of glacial acetic acid and $10 \mathrm{~mL}$ of $10 \%$ buffered formalin. The fat tissue was immersed in this solution for $12 \mathrm{~h}$ overnight in a water bath and was not heated or exposed to heat due to the ether content.

4) An solution of acetic acid and formaldehyde-alcohol (AAF

\begin{tabular}{|c|c|c|c|c|c|}
\hline Author & Year & $\mathrm{N}^{\circ}$; pT STADIUM & $\begin{array}{c}\text { Classic Methods } \\
\text { No metastasis /lymph } \\
\text { nodes }\end{array}$ & Type of clearing method & $\begin{array}{c}\text { Clearing methods } \\
\mathrm{N}^{\circ} \text { metastasis /lymph } \\
\text { nodes }\end{array}$ \\
\hline Pickren [20] & 1961 & $125 ; \mathrm{T} 1-2$ & ---X--- & Pickren clearance solution & $22 / 223$ \\
\hline Haagensen et al. [3] & 1972 & 317; T1-2 & ---X--- & Pickren clearance solution & $1 / 31$ \\
\hline Durkin et al.[10] & 1980 & 100; T1 & ---X--- & Absolute alcohol and shaker & $370 / 500$ \\
\hline Hartveit [17] & 1982 & 15 & ---X--- & Clearance solution & $1 / 63$ \\
\hline Morrow et al. [22] & 1984 & $42 ; \mathrm{T} 1-2$ & $22 / 857$ & Absolute alcohol overnight & $33 / 257$ \\
\hline Kingsley et al. [18] & 1985 & 100 & $211 / 2203$ & Clearance solution & $17 / 412$ \\
\hline Koren et al. [4] & 1997 & 13 & $6 / 79$ & Clearance solution & $14 / 84$ \\
\hline Sternberg et al. [19] & 1997 & 49; T1-2 & $143 / 794$ & Pickren clearing solution & $10 / 60$ \\
\hline Ustün et al. [21] & 1999 & 30 & $46 / 150$ & Clearance solution & $10 / 26$ \\
\hline Jiang et al. [23] & 2007 & 127 & ---X--- & Carnoy clearance solution & $58 / 879$ \\
\hline
\end{tabular}

$\mathrm{N}^{\circ}=$ number of patients; $\mathrm{T}=$ pathological stage of the tumor

Table 1: Summary of lymph node dissection by the classical method and using fat clearance methods in cases of breast cancer according to the results from the literature.

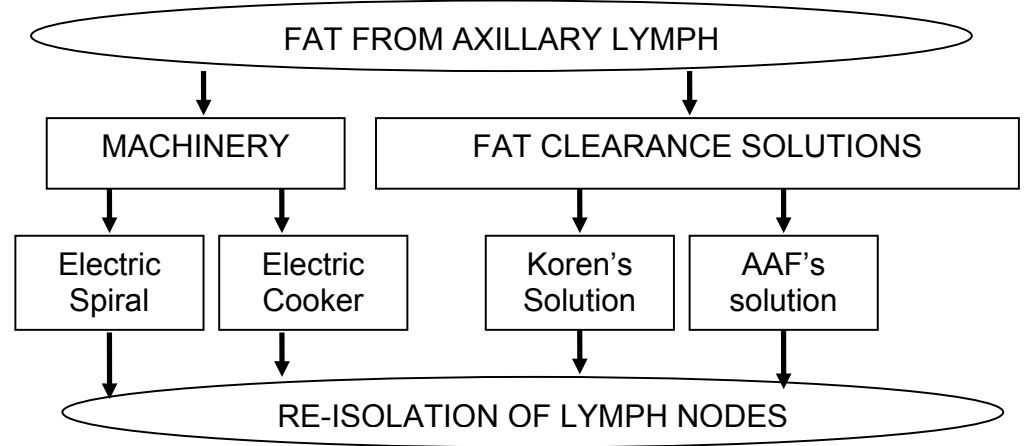

Figure 1: Schematic summary of the methodology used. 

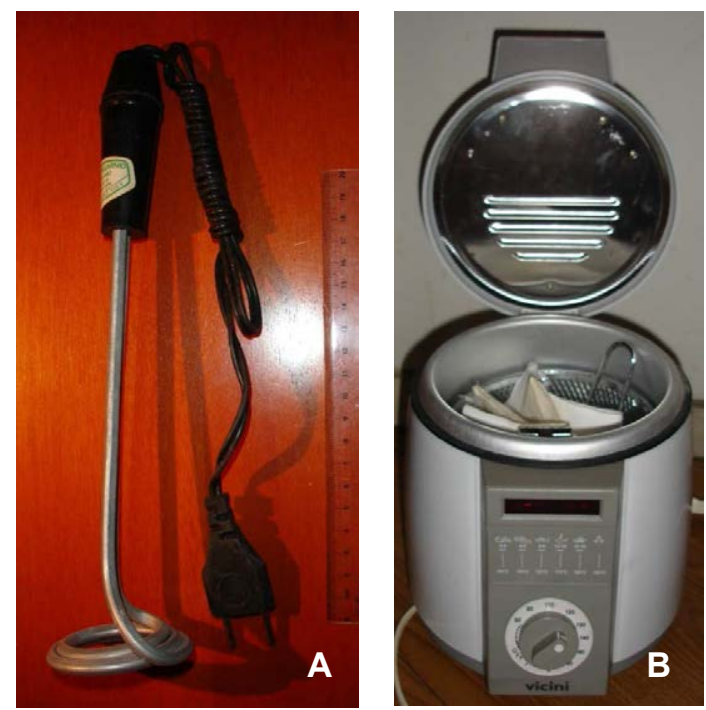

Figure 2: Machinery used: aluminum spiral $(A)$ and electric cooker $(B)$

solution), which is the usual fixative for cell blocks. This solution was prepared with $85 \mathrm{~mL}$ absolute ethyl alcohol (99.3\%), $10 \mathrm{~mL}$ buffered $10 \%$ formaldehyde and $5 \mathrm{~mL}$ glacial acetic acid. The fat tissue was immersed in this solution and placed in an oven at $60^{\circ} \mathrm{C}$ for 15 minutes.

After the methods above were carried out, the fat was re-dissected in search of lymph nodes which were subsequently fixed in $10 \%$ buffered formalin for subsequent paraffin embedding and routine histological processing. Histological sections of $4 \mu$ were obtained from the paraffin block and stained with hematoxylin eosin (HE) to identify and confirm the histopathological diagnoses.

To perform immunohistochemistry on lymph nodes, a tissue microarray (TMA) block containing 100 cores, each $1.0 \mathrm{~mm}$ in diameter and spaced by $2.0 \mathrm{~mm}$ on a $10 \times 10$ grid was constructed [12]. Immunohistochemistry was performed with streptavidin-biotinimmunoperoxidase (Biogenex, USA) using glass slides pre-treated with $4 \%$ aminopropyltrithoxysilane (or "Silane") solution, antibody diluted development system Envision Kit and DAB + (DAKO" Corporation, Carpentry - USA) as chromogen. Labelling in brown, strong, clear and unambiguous on nuclear/ cytoplasmic/ membranous location was considered as positive criterion according to each antibody. Technical details of the antibodies used are noted in Table 2.

The status of the axillary lymph nodes was evaluated by counting the total number of nodes with or without metastasis using the classical method. Then we evaluated the status again with the total number of lymph nodes (classic+clearing methods) and recorded it as follows: no metastasis reported as zero, and when metastasis was found, it was calculated as the total number of lymph nodes with metastasis over the total number of nodes encountered. Metastasis greater than $2.0 \mathrm{~mm}$ were considered as macrometastasis, and metastasis between 0.2 and $2.0 \mathrm{~mm}$ as micrometastasis.

The data was compiled in individual protocols and computed in Microsoft Excel spreadsheets for subsequent analysis in SPSS (Statistic Package for Social Studies) version 17. The level of significance was set at $\mathrm{p}<0.05$.

\section{Results}

Demographics: A total of 100 patients, 98 females and 2 males, made up the study group. Patients were aged from 26 to 84 years $(\mu=$ 59 years); two patients were under 35 years, 20 patients were between 35 and 49 years and the remainder were over 50 years. Seventy-five specimens were obtained through radical mastectomies and the remaining cases from segmentectomy surgical procedures, all of them with axillary dissections. Right breast specimens accomplished 51\% of all cases. Primary tumors were predominantly located in the upper lateral quadrant (30), followed in descending order by the retro areolar region (17), and lateral quadrants of upper quadrants (11 each); union of medial quadrants (nine); inferior lateral quadrant (eight); medial lower quadrant (six); union of the lower quadrants and medial upper quadrant (four each). The predominant histological type was invasive ductal carcinoma (86), followed in descending order by infiltrating lobular types (seven), medullary (three), papillary (two), mixed and metaplastic (one each). The predominant histologic grade was grade II (47), followed by III (23) and I (13) and in 17 cases there was no report of the degree. The size of the primary tumor ranged from 1.0 to $130 \mathrm{~mm}$ ( $\mu=44 \mathrm{~mm}$ ), with a prevalence in size of between 20 to $50 \mathrm{~mm}$ (pT2) in 60 cases, less than $20 \mathrm{~mm}$ (pT1) in 16 cases and greater than $50 \mathrm{~mm}$ (pT3) in 24 cases. From all groups of 25 cases/method, 210 histological blocks were obtained ( $\mu=2$ blocks/case) being 60 blocks $(\mu=2.4)$ from the group treated with Koren modified clearing solution, 55 blocks $(\mu$ $=2.2)$ after the use of the spiral, $48(\mu=1.9)$ submitted to AAF solution and $47(\mu=1.8)$ using the electric pan.

After the use of clearance solutions and machinery, we have found 174 metastasis in a total of 564 lymph nodes, which were not detected in the classical examination. We think this is of paramount importance because that metastasis might change the status and prognosis of the disease. In 95 cases, lymph nodes less than $3.0 \mathrm{~mm}$ were isolated, and metastases were found in 29 in these (Table 3).

The finding of metastatic lymph nodes in three cases and more metastases in eleven cases changed the pathological staging $(\mathrm{pN})$ in 14 patients.

The statistic methods showed that there was no significant difference

\begin{tabular}{|c|c|c|c|c|c|}
\hline $\begin{array}{c}\text { Antibody* } \\
\text { Antipanceratine } \\
\text { (AE1/ AE3) }\end{array}$ & Clone & Isotype & Species & Dilution & Incubation \\
\hline $\begin{array}{c}\text { Anti-LCA } \\
\text { (CD45) }\end{array}$ & PD7 & IgG1, Kappa & Mouse & $1 / 900$ & $\begin{array}{c}\text { Overnight } \\
6{ }^{\circ} \mathrm{C}\end{array}$ \\
\hline Anti-ER $\alpha$ & $1 \mathrm{D} 5$ & IgG1, Kappa & Mouse & $1 / 600$ & $\begin{array}{c}\text { Overnight } \\
6^{\circ} \mathrm{C}\end{array}$ \\
\hline
\end{tabular}

*Manufacturer: DAKO® Corporation, Carpentry - USA; Antigenic reactivation: citrate $\mathrm{pH} 6.0$

Table 2: Antibodies.

\begin{tabular}{|c|c|c|c|c|}
\hline Methods & Classical Method & $\begin{array}{c}\text { Machinery and } \\
\text { clearance solution } \\
\text { methods }\end{array}$ & Total \\
\cline { 2 - 5 } & $\begin{array}{c}\text { Metastasis / lymph } \\
\text { nodes }\end{array}$ & $\begin{array}{c}\text { Metastasis / lymph } \\
\text { nodes }\end{array}$ & $\begin{array}{c}\text { Metastasis / } \\
\text { lymph nodes }\end{array}$ \\
\hline & $121 / 372$ & Pan & $23 / 105$ & $144 / 477$ \\
\hline & $95 / 400$ & Spiral & $51 / 156$ & $146 / 556$ \\
\hline & $90 / 306$ & CS & $61 / 164$ & $151 / 470$ \\
\hline Total & $143 / 348$ & AAF & $39 / 139$ & $182 / 487$ \\
\hline
\end{tabular}

$\mathrm{CS}=$ modified Koren clearing solution; $\mathrm{AAF}=$ formaldehyde-alcohol acetic acid solution

Table 3: Distribution of samples according to the amount of lymph nodes isolates with and without metastasis before and after the use of fat clearing methods and the total. 
Citation: Rodrigues FR, Pires ARC, de Fonseca EC, Antunes SCG, de Oliveira Teixeira CML, et al. (2014) Improved Fat Clearance Techniques for the Examination of Breast Cancer Lymph Nodes. J Cancer Sci Ther 6: 188-194. doi:10.4172/1948-5956.1000270

between the methods. That is the reason for the comparison of the data of four different methods with the classic method. The KruskalWallis test indicates no statistically significant difference $(\mathrm{p}>0.05)$ in the proportion of lymph nodes found after the use of machinery and clearance solutions by the four methods $(\mathrm{H}=2.716, \mathrm{df}=3, \mathrm{p}$-value $=$ 0.438). This means that technological methods are equally effective in detecting lymph nodes. Although there is no difference in the mean proportion of nodes isolated between the methods, there was a trend of greater efficiency of the electric pan method over the modified Koren clearing solution (Figure 3 ). In 70 cases in which the axillary lymph were positive a greater number of lymph nodes were found, whether being metastatic (623) or not (1428) $(\mu=8$ metastases/20 lymph nodes). Immunohistochemistry previously performed on mammary tumors (data collected from the pathology archives) revealed 15 cases were triple negative, and 29 cases were positive for Cerb-B2, 65 for estrogen receptor (ER) and 68 for progesterone receptor (PR). Immunohistochemistry performed on the lymph nodes, after the fat clearance methods, from the TMA block constructed for comparison of the primary tumor and to assess the condition of the material, showed immunoreactivity with anti-LCA (CD45) in 95 cases; the other five cases were represented by fat.

From a total of 100 cases, 27 lymph nodes were ER positive, the same as the findings of exam performed on the breast in 22 cases; the pankeratin (AE1/AE3) immunostaining on the lymph nodes showed positivity in 42 cases, and 26 cases coincided with the positivity of ER on the breast (Figures 4 and 5).

\section{Discussions}

Most patients (77 cases) were over 50 years of age, 40 of them with locally advanced tumors of which some received neoadjuvant treatment
(48 cases) pointing to, in accordance to the literature, the possibility of a worse prognosis and an unfavourable evolution of illness [13]. During this study, three of the patients who died were over 50 years and had histopathological diagnoses of infiltrating ductal carcinoma, two of which positive for microscopic factors for poor prognosis such as $\mathrm{pN} 2$ and $\mathrm{pN} 3$, which are associated with a poor prognosis, neoplastic capsular invasion of the lymph node, extra capsular extension, neoplastic lymphatic and blood emboli, perineural invasion, involvement of skin necrosis, multifocality and multicentricity, and one case triple negative by immunohistochemical staining. According to the literature, the incidence of breast cancer is relatively rare before 35 years of age, with a rapid and progressive increase from 35 until 50 years, with an incidence reduction in the following decades. The two cases under 35 years had a common pathological type (infiltrating ductal carcinoma), large tumors $(>70 \mathrm{~mm})$, high histological grade, a high number of lymph nodes ( $>25$ ), neoplastic emboli nodes, neoplastic invasion of the lymph node capsule, extracapsular extension, lymph node coalescence, an advanced pathological stage (ypT4), hormone receptor positivity and Cerb-B2 positivity. KURU et al. [14] reported that a tumor size greater than $20 \mathrm{~mm}$, a high histological grade (poorly differentiated), neoplastic lymphovascular invasion and a patient aged less than 35 years or greater than 49 years, are associated with poor prognosis.

The average tumor size in our series was large (average $\mathrm{pT}=44 \mathrm{~mm}$ ) probably due to difficulties in the early detection of breast cancer and due to the variety of risk factors and genetic characteristics involved in the etiology [15].

In accordance with the literature, our sample was predominantly female (98\%). When compared to women, breast cancer in men is generally diagnosed at a more advanced stage with lymph node

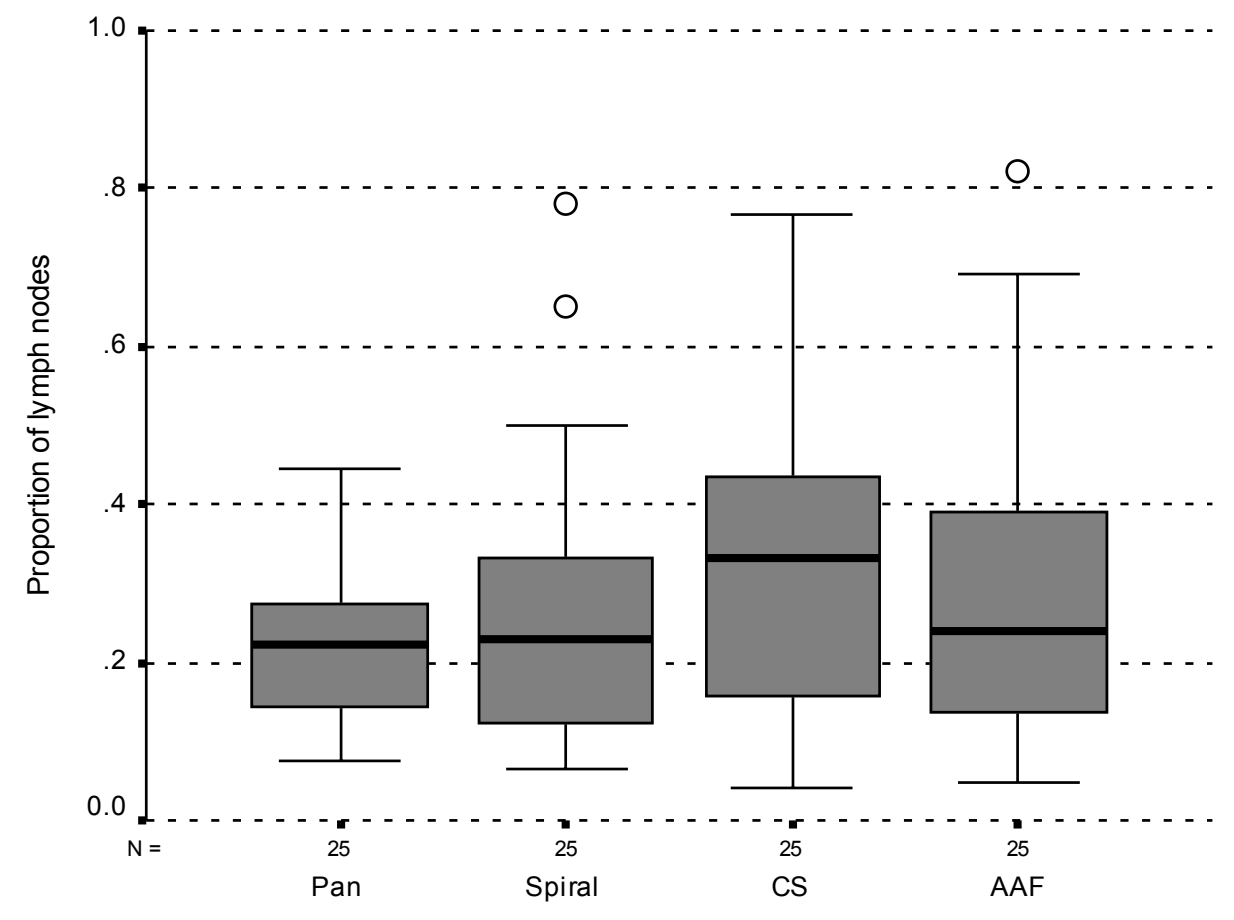

Methods

Figure 3: Box-and-whiskers plots according to the proportion of isolates lymph nodes after the use of clearing methods of fat. 
Citation: Rodrigues FR, Pires ARC, de Fonseca EC, Antunes SCG, de Oliveira Teixeira CML, et al. (2014) Improved Fat Clearance Techniques for the Examination of Breast Cancer Lymph Nodes. J Cancer Sci Ther 6: 188-194. doi:10.4172/1948-5956.1000270

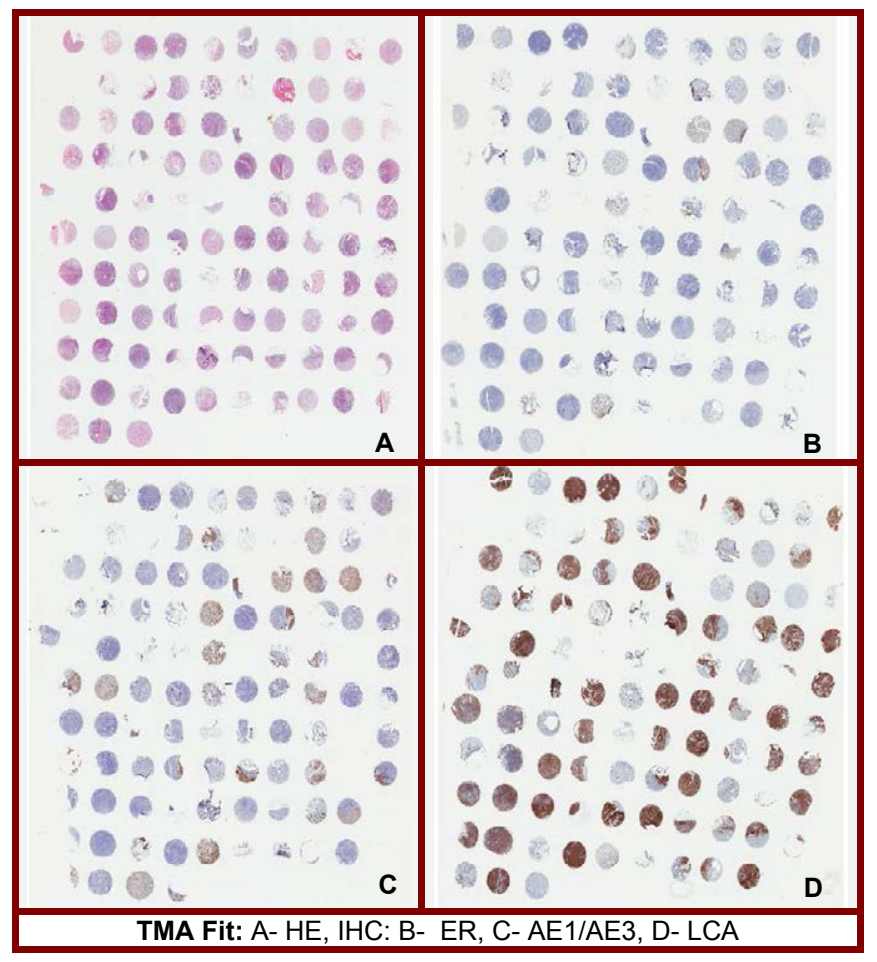

Figure 4: The hematoxylin eosin $(\mathrm{HE})$ and immunohistochemistry $(\mathrm{IHC})$ performed on the TMA block.

metastasis. In acordante to the literature, male incidence was also very low (1\%) in our study [16].

All the substances used in the methods presented here are easily found in pathology laboratories, and proved to be quite fast because the average time spent with the clearing methods of fat immersed in the solutions and cooker was about 15-30 minutes (the optimal time is 15 minutes because analytical artifacts) and another 30 minutes for the manual isolation, except for the overnight procedure described by Koren et al. [4]. Moreover, they are inexpensive highlighting the low price of the electric pan cited in the text which is about US $\$ 100.00$

The danger in using the electric spiral boiler was also noted due to the close proximity of the electricity source and the liquid medium (water), requiring special care and attention from the user due to the risk of fire or electric shock. In addition the boiler's resistance is low, which may cause rapid wear of the machine, and not allowing the control of the medium temperature of the experiment. An industrial thermometer was used here, which is fragile and costly. In relation to the modified clearing solution, Koren et al. [4], care must always be taken with solutions containing ether as they cannot be exposed to any form of heat. We observed no problems with the cooker, which is portable, inexpensive, easy to use and clean, controls the temperature through a display and is environmentally friendly since water is used as a solvent.

However, in one of the five cases from which small lymph nodes were not isolated, a focus of micrometastasis was isolated after the use of modified Koren clearing solution. For this reason the patient was re-staged. Hartveit et al. [17] found 63 negative lymph nodes using a clearance solution and a micrometastasis, which was not found during routine processing.

The methods described here do not dilute the fat completely; instead they clear it, allowing easier identification of lymph nodes, especially those smaller than $4.0 \mathrm{~mm}$. Although most pathologists support the prognostic importance of lymph node isolation, many find the use of fat clearance solutions time consuming and the results to be unreliable $[18,19]$. Two blocks per case were used in this study demonstrating that the methods are inexpensive, easy and fast. Niemann et al. [11] reported that there is no consensus on whether to include all major lymph nodes ( $4.0 \mathrm{~mm}$ or greater), however our study supports the inclusion of all lymph nodes as the results justify the costs, which are not excessive. Koren et al. [4], argue that we must resort to means that can improve the isolation of lymph nodes when less than 10 lymph nodes are detected by the classical method. Although it is debatable, we recommend that a minimum of 20 lymph nodes to be isolated to increase the chances of finding metastatic nodes ( $p=0.0005)$. Durkin and Haagensen [10] and Pickren [20] report increases of $19 \%$ and $22 \%$, respectively, in detecting lymph node metastasis after use of fat clearance solutions. Fat clearance techniques and lymph node dissection allow the detection of those smaller than $1.0 \mathrm{~mm}$. The more lymph nodes examined, the greater the possibility of metastasis identification. The literature is full of articles about the theme, including works showing benefits with the use of these solutions on intestinal fat. We consider that optimizing results in order to minimize errors and to improve specimen's examination is important to the patient. Metastasis was found in some of the additional lymph nodes detected with the application of the proposed
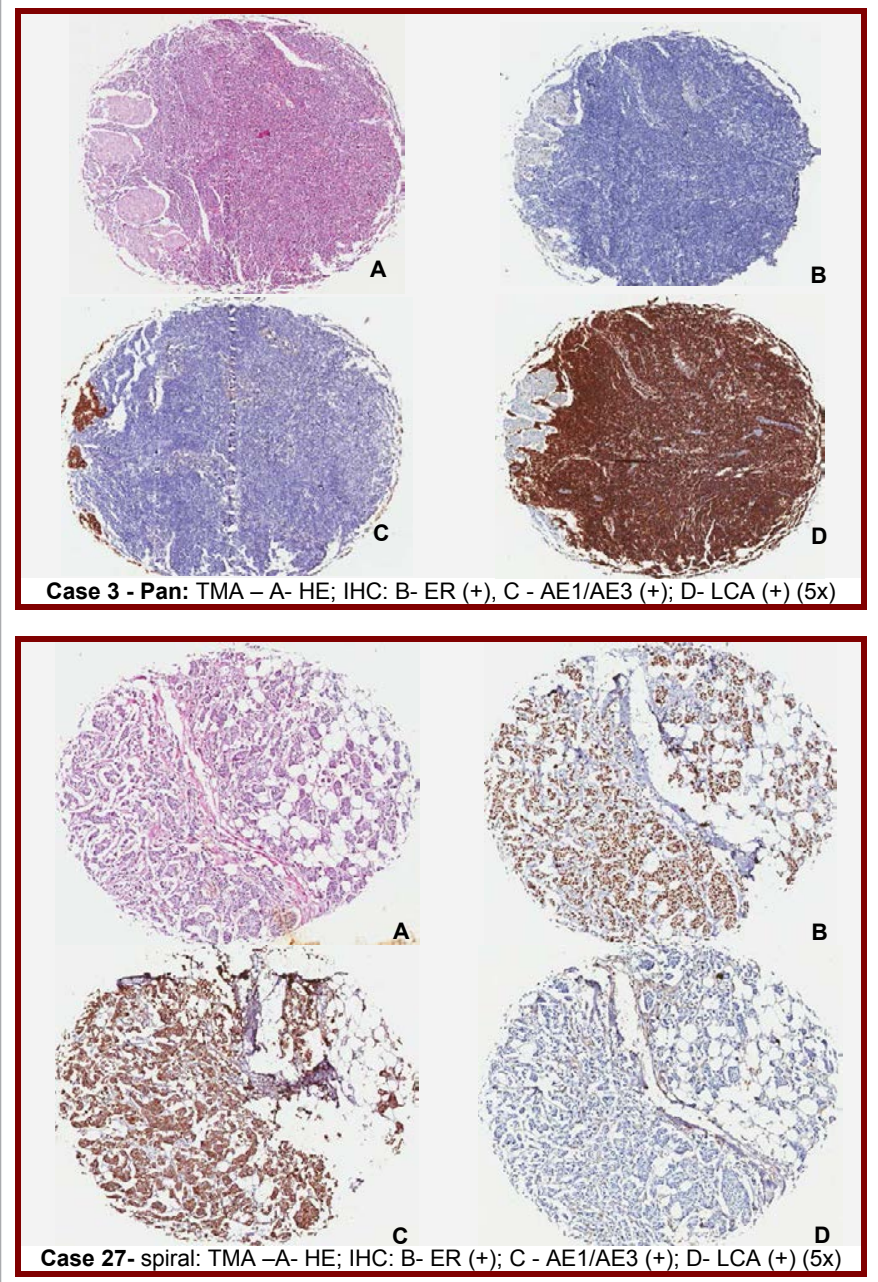

Figure 5: The microscopical performed according to the method used. 
Citation: Rodrigues FR, Pires ARC, de Fonseca EC, Antunes SCG, de Oliveira Teixeira CML, et al. (2014) Improved Fat Clearance Techniques for the Examination of Breast Cancer Lymph Nodes. J Cancer Sci Ther 6: 188-194. doi:10.4172/1948-5956.1000270

methods, changing the stage of the disease. We believe that this result could favor the evaluation of the real prognosis of patients and to design the therapeutic approach.

The largest lymph nodes detected by the classical method and after the use of clearance machinery and solutions were $65 \mathrm{~mm}$ and $28 \mathrm{~mm}$, respectively. Ustun et al. [21] reported lymph nodes of $68 \mathrm{~mm}$ and $42 \mathrm{~mm}$, respectively, showing that our methods have the potential to identify smaller lymph nodes. The average size of lymph nodes in our study was $12 \mathrm{~mm}$. The percentage of lymph node metastasis was higher (62\%) when the diameter of the largest lymph node was found to be smaller than $9.0 \mathrm{~mm}$, probably because the average diameter of the tumor remained constant $(43 \mathrm{~mm})$ and due to the uneven distribution of the number of cases and pathological staging of patients. In the literature no studies relating size and lymph node metastasis were found, but reports on the extent of the largest metastasis. When the metastasis had a diameter between 10 and $19 \mathrm{~mm}$, a greater amount of metastases (98) and lymph nodes (174) were observed. Morrow et al. [22] investigated 42 patients; T1 and T2, using four alcohol washes of progressive concentrations, finding approximately $30 \%$ more lymph nodes after the use of these solutions; however this finding did not change the staging of the patients. Jiang et al. [23] used Carnoy solution composed of $60 \mathrm{~mL}$ absolute ethanol, $30 \mathrm{~mL}$ chloroform and $10 \mathrm{~mL}$ glacial acetic acid, two to three times in 127 breast cancer cases, and found that the pathological staging of lymph nodes $(\mathrm{pN})$ changed in seven cases, from pN0 to $\mathrm{pN} 1$ in four cases, $\mathrm{pN} 1$ to $\mathrm{pN} 2$ in two, and $\mathrm{pN} 2$ to $\mathrm{pN} 3$ in one case, reporting the importance of isolating small lymph nodes.

After optimizing these methods, it was noted that they do not interfere with the quality of materials in routine staining or immunohistochemistry, confirming the observations of the authors in Table 1. (Figures 4 and 5). In accordance to the literature, which reports that $10 \%$ to $15 \%$ of cases are triple negative or basal cases, immunohistochemistry carried out on breast tumors showed that $15 \%$ of cases were triple negative or basal [24]. In our study, the immunohistochemistry performed on the TMA block revealed that the methods used did not interfere with the immunostaining since the antiLCA antibody marked the majority of cases (95\%). Immunostaining for ER in the TMA material showed only $27 \%$ positivity compared to the same techniques performed in breast cancer tissue, which showed $65 \%$ positivity. Nevertheless, studies have reported that there is significant disagreement between the hormone receptors in primary and metastatic breast cancer by up to $37 \%$ of cases according to Broom et al. [25] and up to $30 \%$ of cases, as reported by Lower et al. [26]. Five cases were positive for RE but were negative for the breast cancer tissue, while pan-keratin positivity in several cases presenting with metastasis (42\%) for breast cancer were negative for ER. The respective findings demonstrate the possibility that immunonegativity for ER may be intrinsic to the patient or assigned to different representative areas of the tumor and not related to the interference of the fat clearance methods

In both males, the rate of positivity of ER was between $50 \%$ and $100 \%$. Although breast cancer in men is similar to that of women, notable differences in hormone receptor positivity have been reported, with men having higher rates of positivity ( $81 \%$ ER positivity and $74 \%$ PR positivity) than females whose positivity is $57 \%$ for both receptors [27]. As previously reported, the discrepancy between the positivity of these markers and poor patient outcomes may be related to a delay in diagnosis.

Clearing of the axillary specimen is not necessary to identify cases with macroscopic positive nodes, but it is of paramount importance to identify small axillary lymph nodes and even smaller than $2 \mathrm{~mm}$ and improve the accuracy of staging of lymph nodes in breast cancer. In $76 \%$ of the specimens changed from $\mathrm{pT} 1$ and $\mathrm{pT} 2$ pathological stages. Among those, $14 \%$ had the pathological stage changed to an even higher stage by the use of the applied methods. We think that the contribution of this work is to benefit patients allowing the correct pathological staging and the appropriate therapeutic approach.

The methods of routine histological investigation of the axillary nodes in breast carcinoma shown here adds reliability to the pathologist's report, giving attention to details, but little extra team in laboratory work.

\section{Conclusions}

We conclude that the methods used here present great advantages over the classical method. This study emphasizes that these methods are viable, fast, practical and affordable. They do not interfere with the histological quality of the samples or with the immunohistochemical reactions. We report that these methods are important for internal quality control in the anatomical pathology laboratory, especially when there is discordance between clinical signs of the patient and the clinical report issued, or when the number of nodes is lower than previously expected and / or reported.

\section{Conflict of Interest Statement}

The authors report no conflicts of interest in this work. No grant support or other kind of assistance was obtained.

\section{References}

1. de la Haba J, Gómez A, Dueñas R, Ribelles N, Méndez MJ, et al. (2004) The quotient of number of nodes and tumour size (N/T) from primary breast cancer predicts the clinical course after diagnosis of distant relapse. Eur J Surg Oncol 30: 346-351.

2. Kwon Y, Ro J, Kang HS, Kim SK, Hong EK, et al. (2011) Clinicopathologica parameters and biological markers predicting non-sentinel node metastasis in sentinel node-positive breast cancer patients. Oncol Rep 25: 1063-1071.

3. Haagensen CD, Feind CR, Herter FP (1972) The lymphatics in cancer. 1rd edn Philadelphia: W B. Saunders Co. p 398.

4. Koren R, Kyzer S, Paz A, Veltman V, Klein B, et al. (1997) Lymph node revealing solution: a new method for detection of minute axillary lymph nodes in breast cancer specimens. Am J Surg Pathol 21: 1387-1390.

5. UICC (International Union Against Cancer) (2009) Committee on Clinical Stage Classification and Applied Statistics: TNM 7nd ed.

6. Somner JE, Dixon JM, Thomas JS (2004) Node retrieval in axillary lymph node dissections: recommendations for minimum numbers to be confident about node negative status. J Clin Pathol 57: 845-848.

7. Millis RR, Springall RJ, Hanby AM, Ryder K, Fentiman IS (2002) A high number of tumor free axillary lymph nodes from patients with lymph node negative breast carcinoma is associated with poor outcome. Cancer 94: 2307-2309.

8. Salama JK, Heimann R, Lin F, Mehta N, Chmura SJ, et al. (2005) Does the number of lymph nodes examined in patients with lymph node-negative breast carcinoma have prognostic significance? Cancer 103: 664-671.

9. Motomura K, Egawa C, Komoike Y, Kataoka T, Nagumo S, et al. (2007) Sentinel node biopsy for breast cancer: technical aspects and controversies. Breast Cancer 14: 25-30

10. Durkin K, Haagensen CD (1980) An improved technique for the study of lymph nodes in surgical specimens. Ann Surg 191: 419-429.

11. Niemann TH, Yilmaz AG, Marsh WL Jr, Lucas JG (1998) A half a node or a whole node: a comparison of methods for submitting lymph nodes. Am J Clin Pathol 109: 571-576.

12. Pires AR, Andreiuolo Fda M, de Souza SR (2006) TMA for all: a new method 
Citation: Rodrigues FR, Pires ARC, de Fonseca EC, Antunes SCG, de Oliveira Teixeira CML, et al. (2014) Improved Fat Clearance Techniques for the Examination of Breast Cancer Lymph Nodes. J Cancer Sci Ther 6: 188-194. doi:10.4172/1948-5956.1000270

for the construction of tissue microarrays without recipient paraffin block using custom-built needles. Diagn Pathol 1: 14.

13. Barnett GC, Shah M, Redman K, Easton DF, Ponder BA, et al. (2008) Risk factors for the incidence of breast cancer: do they affect survival from the disease? J Clin Oncol 26: 3310-3316.

14. Kuru B, Camlibel M, Gulcelik MA, Alagol H (2003) Prognostic factors affecting survival and disease-free survival in lymph node-negative breast carcinomas. J Surg Oncol 83: 167-172.

15. Weissenbacher TM, Zschage M, Janni W, Jeschke U, Dimpfl T, et al. (2010) Multicentric and multifocal versus unifocal breast cancer: is the tumor-nodemetastasis classification justified? Breast Cancer Res Treat 122: 27-34.

16. Siegel R, Naishadham D, Jemal A (2012) Cancer statistics for Hispanics/ Latinos, 2012. CA Cancer J Clin 62: 283-298.

17. Hartveit F, Samsonsen G, Tangen M, Halvorsen JF (1982) Routine histological investigation of the axillary nodes in breast cancer. Clin Oncol 8: 121-126.

18. Kingsley WB, Peters GN, Cheek JH (1985) What constitutes adequate study of axillary lymph nodes in breast cancer? Ann Surg 201: 311-314.

19. Sternberg A, Shtelman E, Sandbank J (1997) Fat clearing versus manual dissection in the processing of breast cancer axillary specimens. The Breast 6: $17-20$

20. PICKREN JW (1961) Significance of occult metastases. A study of breast cancer. Cancer 14: 1266-1271.
21. Ustaun MO, Onal B, TuÄŸyan N, Rezanko T (1999) Lymph node revealing solution: is it effective on detecting minute lymph nodes? Adv Clin Path 3: 135138.

22. Morrow M, Evans J, Rosen PP, Kinne DW (1984) Does clearing of axillary lymph nodes contribute to accurate staging of breast carcinoma? Cancer 53: 1329-1332.

23. Jiang J, He QQ, Yang XH, Liang Y, Fan LJ, et al. (2007) Contribution of minute axillary lymph nodes to accurate staging for patients with breast cancer. Chin Med J (Engl) 120: 1762-1765.

24. Silva F, Carvalho S, Milanezi F, Schmitt FC (2008) [Basal-like carcinoma of the breast]. Acta Med Port 21: 373-378.

25. Broom RJ, Tang PA, Simmons C, Bordeleau L, Mulligan AM, et al. (2009) Changes in estrogen receptor, progesterone receptor and Her-2/neu status with time: discordance rates between primary and metastatic breast cancer. Anticancer Res 29: 1557-1562.

26. Lower EE, Glass EL, Bradley DA, Blau R, Heffelfinger S (2005) Impact of metastatic estrogen receptor and progesterone receptor status on survival. Breast Cancer Res Treat 90: 65-70.

27. Marchal F, Salou M, Marchal C, Lesur A, Desandes E (2009) Men with breas cancer have same disease-specific and event-free survival as women. Ann Surg Oncol 16: 972-978. 